\title{
Virtopsy: an aid in forensic investigation
}

\author{
Surabhi $^{1}$, Taniya Malhotra ${ }^{2}$, Sumit Bhateja ${ }^{3 *}$, Geetika Arora ${ }^{4}$ \\ ${ }^{\mathbf{1 - 2}}$ Student, ${ }^{3} \mathrm{HOD},{ }^{4}$ Reader, ${ }^{3}$ Dept. of OMR, ${ }^{4}$ Dept. of Public Health Dentistry, ${ }^{\mathbf{1 - 3}}$ Manav Rachna Dental College, ${ }^{4}$ Inderprastha Dental \\ College, Faridabad, India
}

*Corresponding Author: Sumit Bhateja

Email: surabhimakk@gmail.com

\begin{abstract}
Virtopsy denotes 'virtual autopsy'. Like autopsy, virtopsy is an multidisciplinary approach that combines forensic medicine, pathology, biomechanics and digitized radiographic imaging of human organs and tissues to provide clues for forensic identification of the cause and manner of death. It is a minimally invasive, observer-independent new-age technique in postmortem examination. This article is an overview of the advancing methodology and its potential application in forensic sciences in developing countries.
\end{abstract}

Keywords: Virtopsy, forensic science, radiographic imaging.

\section{Introduction}

An autopsy is a method that surveys the mortel remains of a person for identification of the cause of death. Virtopsy signifies 'virtual autopsy', derived from Latin and Greek languages. It includes imaging methods that are used in clinical medicines routinely such as computed tomography and magnetic resonance imaging used in autopsy, to find the cause of the demise. ${ }^{1}$

Every human being lives to die another day and is sometimes imminent, wherein forensic sciences and methodology becomes a necessity.

Forensic science is a multidisciplinary approach combining various principles such as criminalities and jurisprudence, odontology, pathology, psychiatry including behavioral sciences, questioned documents that includes toxicology and physical anthropology. On the other hand, forensic medicine deals with the examination and identification of relevant medical data in both living and deceased. $^{2}$

The conventional procedures of autopsy included dissection, interpretation and cataloguing and the data collected from the examination was then compiled for arriving at the conclusion. The dead body was then handed over for the last rites to be performed. However, the mutilations involved in the procedure often left the grieving family disturbed. These drawbacks led to the birth of virtopsy. ${ }^{3}$

\section{History}

Although the science of forensic odontology has experienced sharp innovations in criminology and investigative procedures, the prosecutors and defense lawyers were still eager to test new methods to make their case. $^{4}$

Back in late 1990s, this revolution in forensic medicine started off in Switzerland, when the Institute of Forensic Medicine of the University of Bern started collaboration with the Scientific Service of the City Police of Zurich, aiming at documenting the surfaces of objects and bodies in a three-dimensional (3D) manner. In a high profile homicide case, the impressions of the skull of the victim were matched with a most suitable murder tool to focus on the arena of forensic analysis that would minimally disturb the skull of the victim. This instance foreshadowed the birth of virtopsy. 5

Virtopsy included 4 cornerstones namely

1. Three-dimensional (3D) surface scanning 3D/computeraided design photogrammetry

2. Multi-slice computed tomography (MSCT)

3. Magnetic resonance imaging (MRI)

4. MRI spectroscopy

\section{Indications of virtopsy}

The Virtopsy technique which is minimally invasive is applied to a majority of the cases that undergo forensic evaluation. Before autopsy, the post-mortem imaging is often used to plan the autopsy and confirm autopsy findings. In cases of uncertain or unknown identity, the cadaver is thoroughly scanned for radiologic identification for the comparison of ante-mortem data with post-mortem CT.

In cases of train-pedestrian accidents, CT scan data is useful in identifying missing organs or skeletal parts. ${ }^{6}$ Furthermore, CT scan is also able to detect and investigate the density of the object, identify foreign bodies such as medical implants, or projectiles and bullet fragments. Virtopsy method is used in cases of all homicides, deaths under the age of 18 years of age, and complicated cases which gives better results after analyses.

\section{Applications of virtopsy}

Three-dimensional surface scanning /computer-aided design photogrammetry

Here, measurements are made using photographs. Multiple photographs are taken from different angles. TRITOP/ATOS II system (GOM, Braunschweig, Germany) 
software is used to further analyze the photographs which uses high-speed imaging and remote sensing to construct a 3D comprehensive image of the surface features.

\section{Multislice computed tomography (MSCT)}

Multiple sections of hard tissue architecture is made and analyzed.

\section{Magnetic resonance imaging (MRI)}

Multiple sections of soft tissue is made and analyzed. Any changes of the deceased are mentioned.

\section{Magnetic resonance imaging spectroscopy}

Biochemical picture of the deceased is provided. Accurate time of death is mentioned by taking up the metabolites in the brain which lays from the postmortem decomposition.

\section{Micro-computed tomography}

A scanner was developed by The Institute of Medical Physics in Erlangen, Germany, to image and view a 3D volume with an isotropic resolution ranging from 10 to 100 $\mu \mathrm{m}$ for further modifications from any other procedure.

\section{Practice of virtopsy \\ Virtobots}

Virtopsy has evolved in the area of robotics. It uses an allin-one machine called "Virtobot" is an all in one machine which combines all the above mentioned modalities and techniques. This machine gives a sum of combined surface and body volume data acquisition within a single 3D space for better analyzes. $^{8}$

\section{Virtomobile}

Virtobot is a gigantic and a locomotive machine that can be mounted on a trailer and locomoted which can be easily transported to the site of disaster. ${ }^{9}$

\section{Applications of virtopsy in medicine}

A new technology of autopsy has been invented. This technique consists of the internal examination of dead bodies using computed tomography (CT) and magnetic resonance imaging (MRI). It is a conservative procedure without opening the body or body parts and is not ethically harmed as it is not tolerated by certain families or religious groups to open up the dead body. Besides, Virtopsy allows the reconstruction of a $3 \mathrm{D}$ view of the investigated cadaver and gives a better analysis.

In Forensic Medicine, Virtopsy comes into play. These further include the investigation of the anthological investigations, carbonized and putrefied body identifications, cases of mass disaster, age estimation, anthropological examinations and skin lesion analyses. ${ }^{10}$

In cases of drowned individuals, the CT scan is preferred. It gives brief information about the volume, density, size of the lungs and the amount of fluid observed within. These information help in diagnosing the cause of death of an individual.
Furthermore, in cases of firearm projectile injuries it is usually difficult to examine. The problem lies,either sometimes the bullet is not in the body, or diverted by an anatomical structure, or can be in unknown part of the body which may go undiagnosed. Therefore, it is important to know the location of the projectile before the virtopsy is performed. As this further facilitates the examination and gives better analysis. ${ }^{11}$

However in cases of mass disaster cases, for human identification the use of adapted vehicles (e.g. Oshkosh Specialty Vehicles ${ }^{\circledR}$, Clearwater, Florida, United States of America) with imaging machines like virtopsy could provide a high level of positive identifications.

Virtosy in court can also play a major advantage. Virtopsy provides excellent tools for crime and accident evidences. It portrays 3D analysis of internal injuries, 3D true color representations of surface injuries and even 3D scaled models of entire crime scenes and events which is of great help during court scenes. The Virtopsy approach shows critical forensic evidence in an unbiased, which is used as an evidence to laypersons and legal professionals. ${ }^{12}$ Virtopsy also plays a major role amongst living individuals. In living individuals, Virtopsy allows the documentation and analysis of patterned injuries such as bite marks, bruises, lacerations, and abrasions. Documentation is made in three dimension images, true to scale, and allows the comparison of injuries to potential injury caused by instruments.

In photogrammetric 3D imaging the color information is acquired using certain software, which combines the digital photographs of the surface taken from many different angles and used to create a single 3D color image of the object. This further is then matched up with the digital 3D surface image of the object with use of coded and uncoded markers placed on the object.

\section{Application of virtopsy in dentistry}

Virtopsy nowadays is used as an adjunct with radiographic and computed tomographic modalities and is thus considered as an important tool in forensic identification. ${ }^{12}$ Since human dentition consists of multiple identifiers such as missing teeth, crown size, prosthesis, shape of pulp chambers, root arrangement and periodontal status, teeth also play a major role in human identification processes.

Studies on restorative material by ultra-high-resolution are also related to virtual techniques such as different densities of composite material, temporary fillings, and ceramics as expressed in Hounsfield units.

Three processes are used nowadays which allow for dental identification:

1. The comparison between post mortem and ante-mortem data

2. The development of dental post mortem victim profiles and

3. The dental DNA techniques

The prior collection of all the post mortem dental data is considered crucial for dental identification. 
The other additional data is collected from photographic and radiological imaging techniques of the dentition and oral cavity.

Different dental age estimation methods based on toothy development are also considered valuable in virtopsy techniques. $^{12}$

\section{Visualisation: storage, processing and visualization of medical image data \\ Data Storage}

Modern radiological scanners generate huge amounts of data and needs to be stored. DICOM (Digital Imaging and Communication in Medicine) standard was introduced in the early 1990 s to make sure the quality of intra operability between manufacturers. The standard portrays how the amount of data is stored and how this data is necessary for communication. CT and MRI datasets consist of a threedimensional representation of volume pixels. ${ }^{13}$

Medical imaging database is investigated, stored and analyzed by radiologists using a Picture Archiving and Communication System (PACS).

\section{Imaging in Two Dimensions (2D Imaging)}

Since long, the standard means of analyzing the medical imaging volume datasets are transversal, cross-sectional methods. In the process of windowing, a range of Hounsfield values are defined and converted to gray scale values. ${ }^{14}$ Higher values are portrayed as white, lower values are portrayed as black. By using different windows, various pathologies are visualized.

\section{Imaging in Three Dimensions (3D Imaging)}

A two dimensional image of the Cross sectional imaging is obtained while it is actually three dimensional. All PACSs have a Multi Planar Reformation (MPR) tool, allows the investigator to reformat images in the axial, coronal and sagittal image plane. This provides image in three dimension and reviews better analysis.

Other technique to display the image database as a whole is the Volume Rendering procedure. Similar to windowing, a transparency and a color is given to each pixel, based on its Hounsfield value. This 'defining' is called transfer function. As the X-ray densities of different tissues and pathologies are known already, predefined transfer functions allow the depiction of bone, soft tissue and skin in color.

\section{Animation}

The surface scanning produces textured $3 \mathrm{D}$ polygon meshes which are easier to manipulate as it allows repositioning of the models and the reconstruction of a sequence of events based on injury patterns and other facts and shows better results.

An animation software 3D studio MAX is used which allows the polygon models (bones, surface etc.) to be imported directly. A virtual bone system for animation (biped) can be created to better analyze the properties of the polygon model that is to be animated. ${ }^{14}$
In animation, the biped can be viewed into different postures at different point in times, where the animation is then calculated by interpolating between these postures. This procedure is called key framing.

\section{Merits}

Its main advantage is that it is scalpel-free, noninvasive imaging technology. It is an ethical evolution of the technology which has made it easy to transfer the images over the web and is easier for better acceptance for the relatives who do not allow incisions after death of the deceased. The results can be released immediately after scanning which saves time and is an extremely efficient and effective method to study without disturbing the body architecture.

\section{Demerits}

The Developing countries may not support the database and its investment which may not be sufficient to study the data and to provide results. Pathological conditions, status of the infection, organic changes in color, odor and small tissue injuries may not be well defined or missed.

\section{Conclusion}

Presently, the imaging techniques are excellent tools used for forensic medicine. In comparison to other methods; they are able to capture the findings at the moment of investigation without causing any damage and provides better analyses. Capturing indicates the permanent preservation of the document of proof, regardless whether the victim is dead and undergoing post-mortem or surviving. It should be minimally invasive and should cause least harm. Even in dead persons, non-destructive documentation is necessary as it provides information without precluding any other destructive forensic investigation and also it can be used in cultures and situations where autopsy is not supported by different religions or by family members. Furthermore, forensic documentation aims to combine radiological imaging with surface imaging, such as photogrammetric and 3D optical scanning. Also includes the combination of non-invasive imaging with minimally invasive image-guided tissue sampling from anybody location. Virtual autopsy brings about several new advantages, such as easy examination of bodies contaminated by infection, toxic substances, radionuclide or other biohazards. Therefore, imaging has already has come out to be a reliable tool in modern forensic medicine and odontology for a number of applications.

\section{Source of Funding: None.}

\section{Conflict of Interest: None.}

\section{References}

1. Phillip E.O. Shaughnessy. Introduction to Forensic science. DCNA. 2001;45.

2. Cha JG, Kim DH, Kim DH, Paik SH, Park JS, Park SJ Utility of postmortem autopsy via whole-body imaging: Inicial observations comparing MDCT and 3.0T MRI 
findings with autopsy findings. Korean J Radiol 2010; 11:395-406.

3. Rosário AF, Souza PH, Coudyzer W, Thevissen P, Willems $\mathrm{G}$, Jacobs R. Virtual autopsy in forensic sciences and its applications in the forensic odontology. Rev Odonto Cienc 2012; 27:5-9.

4. Pomara C, Fineschi V, Scalzo G, Guglielmi G. Virtopsy versus digital autopsy: Virtuousautopsy. Radiol Med 2009; 114:1367-82.

5. Thali MJ, Braun M, Buck U, Aghayev E, Jackowski C, Vock $P$ et al. (2005). "VIRTOPSY--scientific documentation, reconstruction and animation in forensic: individual and real 3D data based geo-metric approach including optical body/object surface and radiological CT/MRI scanning". $J$ Forensic Sci. 50 (2): 428-42.

6. Bringing ideas to life: Making virtual autopsy a reality - The Edge Malaysia". Infovalley.net.my. 2010-06-07. Retrieved 2013-08-28.

7. Levy AD, Harcke HT, Getz JM, Mallak CT, Caruso JL, Pearse L. Virtual autopsy: Two 11. and three dimensional multidetection CT findings in drowning with autopsy comparison. Radiology 2007;243:862-8

8. Yogish P. Asha Yogish Virtopsy: New phase in forensic odontology. Int J Dent Health Sci. 2015.

9. Thali MJ, Jackowski C, Oesterhelweg L, Ross SG, Dirnhofer R. VIRTOPSY - The swiss virtual autopsy approach. Leg Med (Tokyo) 2007
10. Rajendran R, Sivapathasundharam B. Shafer's Textbook of Oral Pathology. 7th ed. India: Elsevier; 2012. Forensic Odontology. 879-907

11. Jackowski C, Wyss M, Persson A, Classens M, Thali MJ, Lussi A. Ultra-high-resolution dual-source CT for forensic dental visualization-discrimination of ceramic and composite fillings. Int J Legal Med. 2008;122:301-7.

12. Brüschweiler W, Braun M, Dirnhofer R, Thali MJ. Analysis of patterned injuries and injury-causing instruments with forensic 3D/CAD supported photogrammetry (FPHG): An instruction manual for the documentation process. Forensic Sci Int. 2003;132:130-8.

13. Ebert LC, Ptacek W, Naether S, Fürst M, Ross S, Buck U, Weber S, Thali M. Virtobot-a multi-functional robotic system for 3D surface scanning and automatic post mortem biopsy. Int J Med Robot. 2010;6:18-27.

14. Aghayev E, Thali MJ, Sonnenschein M, Jackowski C, Dirnhofer R, Vock P. Post-mortem tissue sampling using computed tomography guidance. Forensic Sci Int. 2007, 166:199-203. 10.1016/j.forsciint.2006.05.035.

15. Patowary AJ. Virtopsy: One step forward in the field of forensic medicine - A review. J Indian Acad Forensic Med. 2008;30:32-6.

How to cite this article: Surabhi, Malhotra T, Bhateja S, Arora G. Virtopsy: an aid in forensic investigation. Int J Forensic Med Toxicol Sci 20194(4):95-8. 